\title{
$\underline{\mathbf{P}-166}$
}

\section{Aspect of Microbial Sources for Pharmaceuticals; Past, Present \& Future}

\author{
S. Orçun Kalkan
}

Ege University, Faculty of Science, Department Biology, 35100 Izmır, Turkey; E-mail: orcunkalkan@yahoo.com

Today, microbiology is a major participant in the global pharmaceutical and neutraceutical industry. The microbes keep on producing novel metabolites as they move into the diverse ecological units. Natural products with industrial applications can be produced from primary or secondary metabolism of living organisms (plants, animals or microorganisms). Owing to technical improvements in screening programs, and separation and isolation techniques, the number of natural compounds discovered exceeds 1 million. Among them, 50-60\% are produced by plants (alkaloids, flavonoids, terpenoids, steroids, carbohydrates, etc.) and 5\% have a microbial origin. Of all the reported natural products, approximately 20-25\% show biological activity, and of these approximately $10 \%$ have been obtained from microbes. Furthermore, from the 22500 biologically active compounds that have been obtained so far from microbes. From the biologically active compounds that have been obtained so far from microbes, $45 \%$ are produced by actinomycetes, $38 \%$ by fungi and $17 \%$ by unicellular bacteria. However, the development of resistance in microbes and tumour cells has become a major problem and requires much research effort to combat it. Microbes have always been a better resource for getting lead molecule with novel scaffold to overcome any such limitation of existing drugs. The significance and frequency of these main types of microbes as producers of bioactive metabolites had varied significantly during the last decades.

Keywords: Microbial metabolites, Secondary metabolites, Pharmaceutical products. 